Journal of Computer Science 5 (3): 172-176, 2009

ISSN 1549-3636

(C) 2009 Science Publications

\title{
Effective Factors on Iranian Consumers Behavior in Internet Shopping: A Soft Computing Approach
}

\author{
${ }^{1}$ Maryam Ghasemaghaei, ${ }^{1}$ Bahram Ranjbarian and ${ }^{2} \mathrm{~S}$. Amirhassan Monadjemi \\ ${ }^{1}$ Department of Management, Faculty of Administrative Science and Economy, \\ University of Isfahan, Isfahan, 81746, Iran \\ ${ }^{2}$ Department of Computer Engineering, Faculty of Engineering, \\ University of Isfahan, Isfahan, 81746, Iran
}

\begin{abstract}
Problem statement: Nowadays, the Internet is increasingly becoming the fastest growing shopping channel in these days. Moreover, it has been predicted that the city of Isfahan in Iran will experience a sharp increase in the Internet and the Web usage in the next decade. However, the factors affect the shopping of different products via the Internet have received a little direct research attention so far. Thus, there is an inherent need to investigate the nature and perceptions of consumers and the suitability of different types of products and services and also the role of each factor which impacts consumers' behavior in choosing between buying from the Internet or traditional stores. Our case study is Isfahan Iran. Approach: The present study aimed to consider the influencing factors on consumer eshopping behavior for different types of products. The data were obtained from 412 volunteers who had the Internet shopping experience and were analyzed using MLP neural networks and logistic regression for each types of product. Then, after comparing the accuracy of these methods, the most important factors which motivate the consumers to buy online were determined by the trained neural network. Results: Compared to the logistic regression, the neural network method showed a better performance in predicting the factors which affect on consumer online shopping behavior with the accuracy of at around $93 \%$ for all types of products included in this study. Conclusion: The results showed that companies should invest on different factors for different types of products to motivate consumers to shop online from them. Again, for each sort of products some factors are more important than the others. This study also suggested the merits of ANNs as non-linear predictors in commercial studies which can be used in reverse engineering as well.
\end{abstract}

Key words: Neural networks, internet shopping, e-commerce, consumer behavior, regression

\section{INTRODUCTION}

The Internet is increasingly becoming the fastest growing shopping channel and this pattern is expected to continue significantly over the next decade. In other words, it is revolutionizing marketing and trade and changing the way companies market and distribute their products and service their customers. Moreover, it is one of the most significant marketing tools in the global marketplace $^{[1]}$.

The Internet allows us to access to a great amount of information in lower costs (both time and money) $)^{[2-5]}$, from inside and outside of our company. Inside the companies, the development of the intranet can greatly facilitate the transmission of information amongst its members ${ }^{[6]}$, while outside the companies, the network not only represents a source of information, but also contributes to improve the relationships amongst the firms and consumers ${ }^{[2,7,9]}$.In this sense, the Internet has propitiated the development of electronic markets, where buyers and sellers of different products converge ${ }^{[5,8,9]}$.

The success of a web store is depend on whether or not it helps to attain a significant amount of potential customers who are willing to make purchases online ${ }^{[10]}$. The basic questions to study are:

- What are the factors which affect the consumers' online buying behavior?

- Are we able to accurately predict consumers' channel choice between web and traditional stores regarding their characteristics?

Some factors are likely to have a profound impact on consumers to choose whether they buy their goods and services through the Internet or in traditional way.

Corresponding Author: Maryam Ghasemaghaei, Department of Management,

Faculty of Administrative Science and Economy, University of Isfahan, Isfahan, 81746, Iran 
For example, prices, physical examination of products, product variety and charges for shipping and handling influences the way consumers decide to purchase their products and on their buying behavior. Also, these factors have a different impact on different product categories.

As electronic commerce over the Internet increases, it will become more important that the Internet marketers have some basis to better market their products or services over the Internet. The more the Internet store marketers understand the underlying reasons for differences in the consumer choices for different kind of products, the more effectively and profitably they can serve their markets ${ }^{[11]}$.

The market forecast is that the city of Isfahan in Iran will experience a sharp increase in the Internet and World Wide Web (WWW) usage towards the near future. However, the factors effects on the shopping of different products via the Internet and in the traditional stores have received little direct research attention so far. Thus, there is an inherent need to investigate the nature and perceptions of consumers and the suitability of different types of products and services and also the role of each factor which impacts on the consumers' behaviors in choosing between buying through the Internet or traditional stores, in Isfahan.

Therefore, this research sets out to illuminate how consumers choose shopping from the Internet or traditional stores using intelligent and soft computing approach, namely the artificial neural networks. We also attempt to determine the factors that impact on consumer's purchasing behavior for different types of products.

\section{MATERIALS AND METHODS}

The data gathering instrument was a selfadministered questionnaire which has been pretested. Based on the feedbacks, the questionnaire was modified and some revision has been made. The statistical population of our study was the actual Internet shoppers who make their shopping through one of the most famous companies which acts as an intermediary for web stores in Iran. A number of 28000 questionnaires were e_mailed to these people and to motivate them to participate in the survey some gifts were proposed. But the response rote was around $1.5 \%$. In other words, only 412 usable questionnaires were gathered.

In this study, we focus on the following factors to assess customers' attitude toward web stores shopping:

- Prices

- Amount of time spend to search for product
- Amount of time and effort spend to gather information about products

- Possibility of comparing products

- Possibility of acquiring more information from seller

- Physical examination of products

- Immediate possession of products

- Uncertainty about getting the right item

- Ability to compare different brands

- Post purchase service

- Possibility of returning in case of damage or dislike

- Quality of the merchandise

- Charges for shipping and handling

- The importance of the brand

- Feature of the web site

- Having experience in buying from a special site

- The effect of advertising

Due to the nature of web stores, all products are not equal on the web and therefore all products are not suitable for sale at web stores. Because different products may have different customers' acceptance levels at web stores, six product categories selected as representatives in our survey questionnaire. The characteristics of survey products are showed in the below:

- Books and magazines: Literature and information products

- Movie and music CDs and DVDs: Entertaining products with very low cost, most of the customers are young and with low budgets, also they are naturally close to the e-shopping

- Makeup: Consumptive and leisured product bought with high involvement

- Domestic tools: Durable product with relatively higher cost and requiring maintenance

- Food: Essential and perishable products

- Clothes: Products with special needs to physical trial

In this study, the perceived performance of web stores on each attribute for each product category was measured with simple scales using the perceived performance of the traditional retail on each attribute as the benchmark. To measure consumers' perception of each channel attribute for each product, we used questions like "Compared with buying from traditional stores, how you would describe the quality of the following items when buying from a web store?" Respondents were asked to indicate their perception of 
each attribute for web stores on a five-point ordinal scale.

For measuring consumers' perceptions of attribute performance on web stores, we assessed a behavioral response regarding consumer patronage. Our survey asked "Compared with buying in traditional stores, how likely are you to buy the following items from a web store?" Response options ranged from 0(absolutely no) to 10 (absolutely yes). The behavioral response variable was then converted to a binary variable with 1 representing a "web store shopper" and 0 representing a "traditional store shopper." Note that, in reality, customers may buy the same products from different channels. Therefore, a web (traditional) store shopper can be interpreted as a shopper with a higher propensity to shop from a web (traditional) store.

\section{RESULTS}

To compare the performance of the neural network approach with that of the logistic regression approach, we compare their accuracy and their MSE (mean square error) to decide which one in better for predicting the factors which can influence on consumers to shopping online. For doing this, we applied a standard five-fold cross-validation method and trained the data by using neural network and averaged the predictive accuracy and their MSE of 15 cross-validation runs and then compare it with the results of logistic regression for each product which is showed in Table 1 .

As can be seen in Table 1, we can conclude that the neural network method produced a better performance across all types of products.

For considering the influencing factors that motivate consumers to shop online, we apply neural network models because it has higher accuracy with lower MSE comparing with logistic regression.

As we said before, there are 17 factors as the input of the neural networks. For determine the factors which influence consumers' behaviors in shopping on the Internet, we omit each factor and measure the amount of accuracy and the error of the network. We did it 15 times for each factor and then we measure the average of the accuracy and error for having better results. If the average of the accuracy of the network was more than 0.75 , we do not consider it as an influencing factor, however, if the average of the accuracy of the network was lower than 0.75 , we consider it as an influencing factor. The results are showed in Table 2.

Table 1: Predictive Accuracy of Neural Networks (ANN) and logistic regression (Log Reg)

\begin{tabular}{|c|c|c|c|c|c|c|c|c|c|c|c|c|}
\hline & \multicolumn{2}{|l|}{ Clothes } & \multicolumn{2}{|l|}{ Food } & \multicolumn{2}{|c|}{ Domestic tools } & \multicolumn{2}{|l|}{ Makeup } & \multicolumn{2}{|c|}{ Movie and music } & \multicolumn{2}{|c|}{ Books and magazines } \\
\hline & Log Reg & ANN & Log Reg & ANN & Log Reg & ANN & Log Reg & ANN & Log Reg & ANN & Log Reg & ANN \\
\hline $\begin{array}{l}\text { Accuracy } \\
(\%)\end{array}$ & 79.21 & 93.50 & 77.79 & 93.60 & 81.60 & 92.80 & 61.35 & 92.30 & 78.99 & 92.5 & 78.96 & 93.70 \\
\hline MSE (\%) & 4.19 & 1.45 & 4.77 & 1.47 & 3.18 & 1.29 & 7.14 & 0.89 & 4.28 & 1.8 & 3.65 & 1.63 \\
\hline
\end{tabular}

Table 2: Factors affecting consumers' behavior on the Internet shopping by omitting each input variable

\begin{tabular}{|c|c|c|c|c|c|c|c|}
\hline \multirow{2}{*}{$\begin{array}{l}\text { Sr. } \\
\text { No. }\end{array}$} & \multirow[b]{2}{*}{ Factors } & \multicolumn{6}{|l|}{ Product category } \\
\hline & & Book and magazine & Movie, $\mathrm{CD}$ and music & Makeup & Domestic tools & Food & Cloth \\
\hline 1 & Prices & 69.95 & 73.92 & 70.85 & 70.60 & 73.02 & 77.14 \\
\hline 2 & $\begin{array}{l}\text { Amount of time spend to search for } \\
\text { product }\end{array}$ & 75.65 & 79.81 & 73.58 & 74.46 & 79.79 & 78.19 \\
\hline 3 & $\begin{array}{l}\text { Amount of time and effort spend } \\
\text { to gather information about products }\end{array}$ & 74.98 & 78.68 & 75.74 & 74.37 & 78.07 & 77.00 \\
\hline 4 & Possibility of comparing products & 72.36 & 74.51 & 72.93 & 72.81 & 76.83 & 77.80 \\
\hline 5 & $\begin{array}{l}\text { Possibility of acquiring more } \\
\text { information from seller }\end{array}$ & 75.58 & 76.03 & 73.25 & 75.09 & 79.95 & 77.90 \\
\hline 6 & Physical examination of products & 77.14 & 78.41 & 72.13 & 70.19 & 76.17 & 73.29 \\
\hline 7 & Immediate possession of products & 74.69 & 76.57 & 75.28 & 75.51 & 75.48 & 75.17 \\
\hline 8 & Uncertainty about getting the right item & 76.77 & 75.38 & 74.02 & 75.05 & 76.46 & 76.07 \\
\hline 9 & Ability to compare different brands & 74.15 & 69.77 & 72.53 & 69.53 & 72.66 & 75.63 \\
\hline 10 & Post purchase service & 76.57 & 76.63 & 71.28 & 69.74 & 76.69 & 74.83 \\
\hline 11 & $\begin{array}{l}\text { Possibility of returning in case } \\
\text { of damage or dislike }\end{array}$ & 74.08 & 74.69 & 72.24 & 68.19 & 74.07 & 72.76 \\
\hline 12 & Quality of the merchandise & 68.43 & 69.58 & 71.26 & 68.97 & 76.87 & 75.30 \\
\hline 13 & Charges for shipping and handling & 76.60 & 74.87 & 70.22 & 73.22 & 76.28 & 73.17 \\
\hline 14 & The importance of the brand & 74.04 & 73.00 & 66.14 & 66.80 & 72.55 & 73.51 \\
\hline 15 & Feature of the web site & 72.83 & 71.36 & 71.94 & 70.19 & 75.54 & 73.99 \\
\hline 16 & $\begin{array}{l}\text { Having experience in buying in a } \\
\text { special site }\end{array}$ & 71.65 & 73.00 & 69.04 & 68.16 & 73.12 & 69.36 \\
\hline 17 & The effect of advertising & 66.49 & 67.62 & 68.38 & 68.24 & 72.74 & 72.89 \\
\hline
\end{tabular}


J. Computer Sci., 5 (3): 172-176, 2009

Table 3: Factors which considered as the influencing ones

\begin{tabular}{|c|c|c|c|c|c|c|c|}
\hline \multirow{2}{*}{$\begin{array}{l}\text { Sr. } \\
\text { No. }\end{array}$} & \multirow[b]{2}{*}{ Factors } & \multicolumn{6}{|l|}{ Product category } \\
\hline & & Books and magazines & Movie and music & Makeup & Domestic tools & Food & Clothes \\
\hline$\overline{1}$ & Prices & $\sqrt{ }$ & $\sqrt{ }$ & $\sqrt{ }$ & $\sqrt{ }$ & $\sqrt{ }$ & \\
\hline 2 & $\begin{array}{l}\text { Amount of time spend to } \\
\text { search for product }\end{array}$ & & & $\sqrt{ }$ & $\sqrt{ }$ & & \\
\hline 3 & $\begin{array}{l}\text { Amount of time and effort spend } \\
\text { to gather information about products }\end{array}$ & $\sqrt{ }$ & & & $\sqrt{ }$ & & \\
\hline 4 & Possibility of comparing products & $\sqrt{ }$ & $\sqrt{ }$ & $\sqrt{ }$ & $\sqrt{ }$ & & \\
\hline 5 & $\begin{array}{l}\text { possibility of acquiring more } \\
\text { information from seller }\end{array}$ & & & $\sqrt{ }$ & & & \\
\hline 6 & Physical examination of products & & & $\sqrt{ }$ & $\sqrt{ }$ & & $\sqrt{ }$ \\
\hline 7 & Immediate possession of products & $\sqrt{ }$ & & & & & \\
\hline 8 & Uncertainty about getting the right item & & & $\sqrt{ }$ & & & \\
\hline 9 & Ability to compare different brands & $\sqrt{ }$ & $\sqrt{ }$ & $\sqrt{ }$ & $\sqrt{ }$ & $\sqrt{ }$ & \\
\hline 10 & Post purchase service & & & $\sqrt{ }$ & $\sqrt{ }$ & & $\sqrt{ }$ \\
\hline 11 & $\begin{array}{l}\text { possibility of returning in case } \\
\text { of damage or dislike }\end{array}$ & $\sqrt{ }$ & $\sqrt{ }$ & $\sqrt{ }$ & $\sqrt{ }$ & $\sqrt{ }$ & $\sqrt{ }$ \\
\hline 12 & Quality of the merchandise & $\sqrt{ }$ & $\sqrt{ }$ & $\sqrt{ }$ & $\sqrt{ }$ & & \\
\hline 13 & Charges for shipping and handling & & $\sqrt{ }$ & $\sqrt{ }$ & $\sqrt{ }$ & & $\sqrt{ }$ \\
\hline 14 & The importance of the brand & $\sqrt{ }$ & $\sqrt{ }$ & $\sqrt{ }$ & $\sqrt{ }$ & $\sqrt{ }$ & $\sqrt{ }$ \\
\hline 15 & Feature of the web site & $\sqrt{ }$ & $\sqrt{ }$ & $\sqrt{ }$ & $\sqrt{ }$ & & $\sqrt{ }$ \\
\hline 16 & $\begin{array}{l}\text { Having experience in buying } \\
\text { in a special site }\end{array}$ & $\sqrt{ }$ & $\sqrt{ }$ & $\sqrt{ }$ & $\sqrt{ }$ & $\sqrt{ }$ & $\sqrt{ }$ \\
\hline 17 & The effect of advertising & $\sqrt{ }$ & $\sqrt{ }$ & $\sqrt{ }$ & $\sqrt{ }$ & $\sqrt{ }$ & $\sqrt{ }$ \\
\hline
\end{tabular}

\section{DISCUSSION}

In the present study, 17 factors were given to the neural networks as inputs. The factors which considered as the influencing ones are depicted with $\sqrt{ }$ in Table 3. As that Table shows, factors no. 11, 14, 16 and 17 are the most effective according to the neural networks trained. A reverse engineering scheme was employed after a complete and successful train to mark the most important factors in the Internet shopping for each group of products respectively. Factors no. 1, 9 and 13 are of importance next. Study of those effective factors could be of essence for people who involve in the emarketing, in particular in Iran. The role of possibility of returning, e-shopping experience and brand are interesting and worth to be analyzed more. Again, web site design, prices, comparability are amongst the influencing factors. The results suggest that although the neural networks are assumed as black boxes, the applied reverse engineering scheme can extract some means from a trained net weights set. E.g., it can be justified that which input features are redundant, less important, or highly effective.

\section{CONCLUSION}

In this study, we developed neural networks and logistic regression models to predict the factors that influence consumers' behavior for different types of products to motivate them for shopping through the
Internet which help companies to invest on these factors for reaching higher profit. In order to identify new predictors of customers' online buying behavior, we conducted an empirical survey for the study. Specifically, in the survey, purchases from web stores were contrasted with purchases from traditional stores for six distinct product categories. The respondents' perceived attribute performance was then used to predict the most important factors that effect on their choice between web and traditional stores. We have provided statistical evidence that neural networks significantly outperform logistic regression models for all types of products in terms of the predictive power.

\section{REFERENCES}

1. Samiee, S., 1998. The internet and international marketing: Is there a fit? J. Interact. Market., 12: 5-21. DOI: $10.1007 / \mathrm{s} 10843-006-7853-0$

2. Boyle, B. and L. Alwitt, 1999. Internet use within the us plastics industry. Ind. Market. Manage., 28: 32-41. DOI: 10.1016/S0019-8501(98)00012-1

3. Min, H. and W. Galle, 1999. Electronic commerce usage in business-to-business purchasing. Int. J. Operat. Prod. Manage., 19: 9-21. DOI: 10.1108/01443579910280232

4. Avlonitis, G. and D. Karayanni, 2000. The impact of internet use on business-to-business marketing: Examples from American and European companies. Ind. Market. Manage., 29: 41-59. DOI: 10.1016/S0019-8501(99)00071-1 
5. Tang, J., D. Shee and T. Tang, 2001. A conceptual model for interactive buyer-supplier relationship in electronic commerce. Int. J. Inform. Manage., 21: 49-68. DOI: 10.1016/S0268-4012(00)00050-5

6. Osmonbekov, T., D. Bello and D. Gilliland, 2002. Adoption of electronic commerce tools in business procurement: Enhanced buying center structure and processes. J. Bus. Ind. Market., 17: 51-66. DOI: 10.1108/08858620210419781

7. Anandarajan, M., A. Anandarajan and H. Wen, 1998. Extranet: Tools for cost control in a value chain framework. Ind. Manage. Data Syst., 98: 29-38. DOI: $10.1108 / 02635579810213125$

8. Pant, S., R. Sethi and M. Bhandari, 2003. Making sense of the e-supply chain landscape: An implementation framework. Int. J. Inform. Manage., 23: 20-21. DOI: 10.1016/S02684012(03)00025-2
9. Samaniego, M., M. Arranz and R. Cabezudo, 2006. Determinants of internet use in the purchasing process. J. Bus. Ind. Market., 21: 164-174. DOI: 10.1108/08858620610662813

10. Chiang, W., D. Zhang and L. Zhou, 2004. Predicting and explaining patronage behavior toward web and traditional stores using neural networks: A comparative analysis with logistic regression. Decision Support Syst., 41: 514-531. DOI: $10.1016 /$ j.dss.2004.08.016

11. Ian, P. and S. Poon, 2000. Factors influencing the types of products and services purchased over the internet. Internet Res. Elect. Network. Appli. Policy, 10: 102-113. DOI: $10.1108 / 10662240010322894$ 